\title{
Variable Correlation of Grid Coordinates to Core Location in Template Prostate Biopsy
}

\author{
Christopher M. Brede ${ }^{a} \quad$ Nicholas J. Douville ${ }^{b} \quad J . S t e p h e n$ Jones $^{a}$
}

aGlickman Urological and Kidney Institute, Cleveland Clinic, Cleveland, Ohio; ${ }^{\mathrm{b} D e p a r t m e n t}$ of Biomedical Engineering, University of Michigan, Ann Arbor, Mich., USA

\section{Key Words}

Prostate biopsy • Template $\cdot$ Prostate cancer • Focal therapy

\begin{abstract}
Purpose: Transperineal template prostate biopsy has been proposed to facilitate systematic biopsy in patients undergoing repeat biopsy who are at high risk for cancer. Advocates tout the reliability of the grid to define biopsy location compared to hand-held transrectal ultrasound guided biopsy. However, accuracy of the biopsy needle depends on bevel position, tissue deformity, and technique. Due to this potential for error, we sought to determine whether the use of transperineal template biopsy would assure reproducibly accurate needle placement. Materials and Methods: A standard $0.5 \mathrm{~cm}$ brachytherapy grid was utilized for transperineal biopsy. A single grid hole was used to obtain biopsies. The bevel of the needle was rotated to a different position with each biopsy, and the angle of the needle was varied to test the ability of the grid to "map" the prostate. Results: We observed wide variation of needle location through a single brachytherapy grid hole. We are able to show that at $5 \mathrm{~cm}$ depth, an area of $2.47 \mathrm{~mm}^{2}$ is possible to biopsy and at a depth of $25 \mathrm{~cm}$; approximately $7.56 \mathrm{~mm}^{2}$ is possible to biopsy. This gives a precision of biopsy of at the most shallow depth $22 \%$ and at the deepest $7 \%$. Conclusion: There is potential for technical and equipment associated error with transperineal template guided prostate biopsy. The grid alone can account for substantial sources of error, so technique remains critical if the grid coordinates are to be used to predict presence or extent of cancer.
\end{abstract}

Copyright $\odot 2012$ S. Karger AG, Basel

\section{KARGER}

Fax +4161306 1234

E-Mail karger@karger.ch

www.karger.com
(C) 2012 S. Karger AG, Basel

1015-9770/12/0064-0194\$38.00/0

Accessible online at:

www.karger.com/cur

\section{Introduction}

Standard extended transrectal ultrasound prostate biopsy fails to identify one third or more cases of prostate cancer [1]. Patients with previous prostatic intraepithelial neoplasia (PIN) or atypia on biopsy have been shown to have increased risk of cancer on repeat biopsy [2]. Men with larger prostates appear to be more likely to have cancer missed by initial biopsy [3]. Villers et al. [4] have shown using MRI and histopathological correlation that the cancers missed by transrectal biopsy may be preferentially located in the anterior portion of the gland, probably because of under sampling of that area during transrectal ultrasound prostate biopsy.

As a result of these limitations of transrectal biopsy, several authors and speakers at national and international meetings have proposed use transperineal biopsy facilitated by the presumed standardization provided by use of a brachytherapy template. The hope is that a grid approach will facilitate precise systematic investigation of all regions of the prostate. Despite using a systematic approach via the brachytherapy grid to repeat biopsy, advocates have not accounted for potential error introduced through the biopsy technique, needle bevel, and equipment used. Due to this potential error, we hypothesized that the use of transperineal template biopsy cannot preclude substantial operator error.

\section{Materials and Methods}

We employed a Civco AccuCARE grid (Civco Medical Solutions, Kalona, Iowa, USA) along with a standard positioner and 
stabilizer system in order to perform transperineal template guided prostate biopsy. A side-fire transrectal ultrasound probe equipped with a Bard MaxCore biopsy needle (C.R. Bard, Inc., Covington, Georgia, USA) was used. The grid was placed firmly against the perineum after pulling scrotum out of the way, in order to minimize the potential for misleadingly manipulating the needle once it passed through the grid. A single grid position (coordinate E3.5) was chosen and 4 biopsy cores were taken sequentially through that hole in the grid at the same depth in the transverse plane. The biopsy probe was never repositioned. The bevel of the needle was rotated to a different position with each biopsy taken. Furthermore, the needle handle was manually displaced in an attempt to alter the needle's trajectory within the hole in the grid, based on the diameter of the needle being smaller than the diameter of the hole.

Next, the sagittal transducer was deployed and similarly to above, the same grid position was chosen. Two biopsy cores were taken with the needle bevel at 180 degrees to each other and the needle handle directed to allow the needle to move the same direction within the grid without changing the position of the ultrasound probe.

Ultrasound images were obtained during each biopsy core and used to demonstrate the position the needle reached during each pass.

Calculations were subsequently made of the geometric concepts that played into the variability of the needle trajectory (i.e. diameter of needle and hole, depth of biopsy).

\section{Results}

The results of the template guided biopsy trajectory are shown in figure 1 (sagittal) and 2 (transverse). The biopsy needle is outlined in each series.

Figure 3A displays the geometric concepts described herein. The 18 gauge biopsy needle has an outer diameter of $1.27 \mathrm{~mm}$ (w1) and a cross sectional area of $1.27 \mathrm{~mm}^{2}$. The inner diameter of 18 gauge needle is $0.838 \mathrm{~mm}$. Therefore, the area of tissue being biopsy is $0.5515 \mathrm{~mm}^{2}$. The grid hole has a diameter of $1.334 \mathrm{~mm}(\mathrm{~d} 1)$ and an area of $1.40 \mathrm{~mm}^{2}$. The difference between these makes the needle represent $90 \%$ of the grid hole. The thickness of the grid is $19.24 \mathrm{~mm}(\times 1)$. Theta $(\theta)$ is the maximum angle the biopsy needle can make within the grid. Please note that the illustration intentionally exaggerates the potential for needle deviation within the grid to allow easier visualization of the concept.

Furthermore, one can calculate the actual area of tissue able to be sampled with a single biopsy through a single grid position, as seen in the cartoon depiction in figure $3 \mathrm{~B}$. By assuming a rigid biopsy system and not accounting for needle deflection due to needle bevel, at biopsy needle depth of up to $25 \mathrm{~cm}$, an area of approximately $7.56 \mathrm{~mm}^{2}$ is possible to biopsy. The certainty of obtaining biopsy tissue from a single grid hole at this depth is
$7 \%$. These data, as well as calculations for biopsies taken at other depths, are shown in table 1.

\section{Discussion}

Transperineal template guided prostate biopsy has been studied as a method for more accurately mapping and sampling tissue from high-risk individuals with previously negative biopsies, and several insurance companies now cover its use. Further, it has been proposed as a method to determine cancer location in order to direct focal therapy using ablative techniques such as cryotherapy, high intensity focused ultrasound.

Igel et al. [5] initially reported their method of transperineal ultrasound guided template biopsy for high-risk patients with prostate specific antigen (PSA) velocity $>$ $0.75 \mathrm{ng} / \mathrm{ml} / \mathrm{y}$, PSA > $10 \mathrm{ng} / \mathrm{ml}$, or previous PIN on biopsy. The population included men with mean age of 65 years, PSA $13.1 \mathrm{ng} / \mathrm{ml}$, and who had previously undergone biopsy $(>$ or $=1)$ with an average of 15.1 cores total. An overall detection rate of cancer using this method was $43 \%$. In a follow-up study of 210 patients, $37 \%$ were found to have prostate cancer and $33 \%$ of patients with former PIN or atypia were found to have cancer [6]. A similar technique was used for 50-core saturation biopsy, which achieved a cancer detection rate of $42 \%$ in a similarly selected group of men [7].

It has been suggested that templates control the trajectory of the biopsy gun and therefore samples can be distributed uniformly and consistently throughout the prostate without error. The hypothesis of our study came from the repeated observation that thermocouples used during cryosurgical ablation for prostate cancer characteristically deviate significantly from this trajectory defined by any given needle hole. Based on the difference between the outer diameter of the thermocouple and the inner diameter of the grid hole, thermocouples have to be repositioned routinely during these cases. Based on the similar diameter of the biopsy needle, we hypothesized that it would deviate even more with purposeful attempts to direct the needle at varying angles within the grid hole. Furthermore, we hypothesized that the needle bevel would add further unpredictability to biopsy needle placement, and that even with the grid firmly against perineum, we would be able to observe similar or exaggerated movement of the biopsy needle across most of the prostate.

In fact, we have demonstrated in our example that there is the potential for a wide variability of biopsy core 


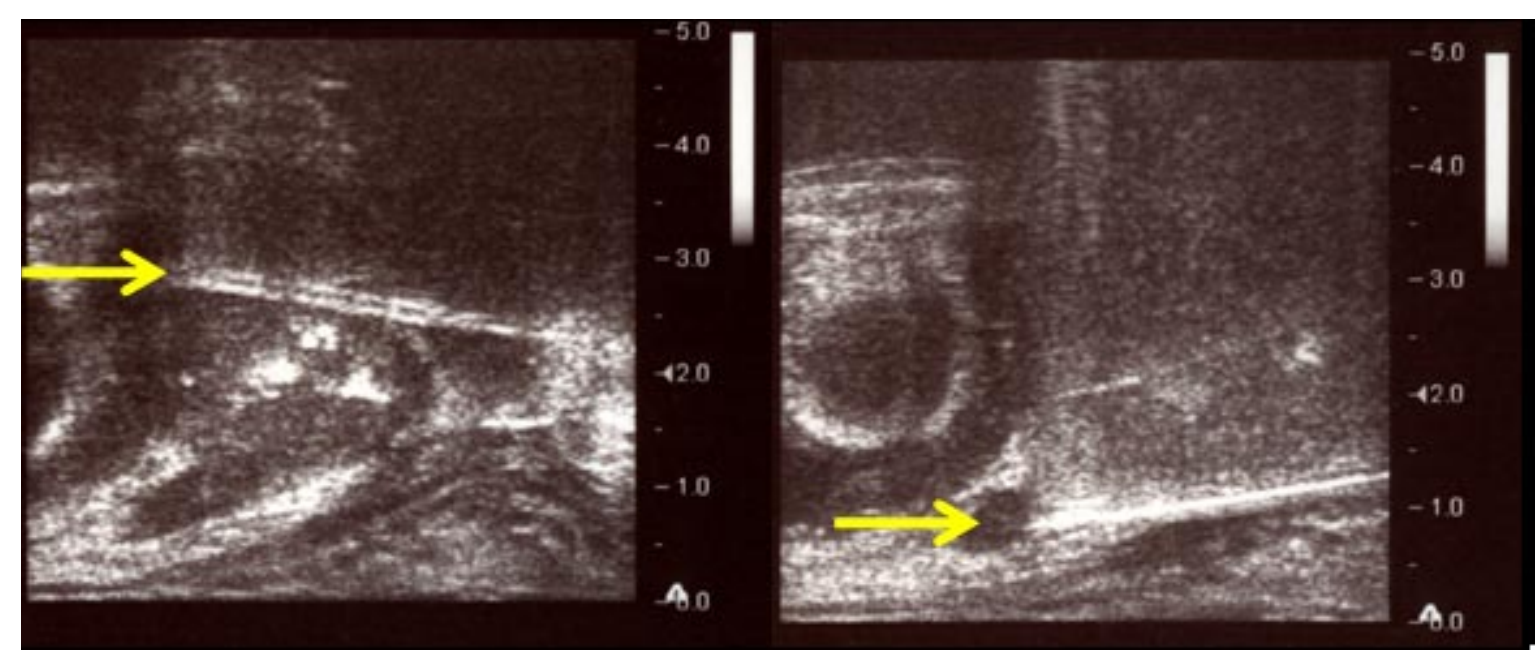

Fig. 1. Sagittal TRUS-bx images demonstrating the range from the anterior to posterior gland of potential biopsy through a single grid coordinate (needle highlighted with arrow)

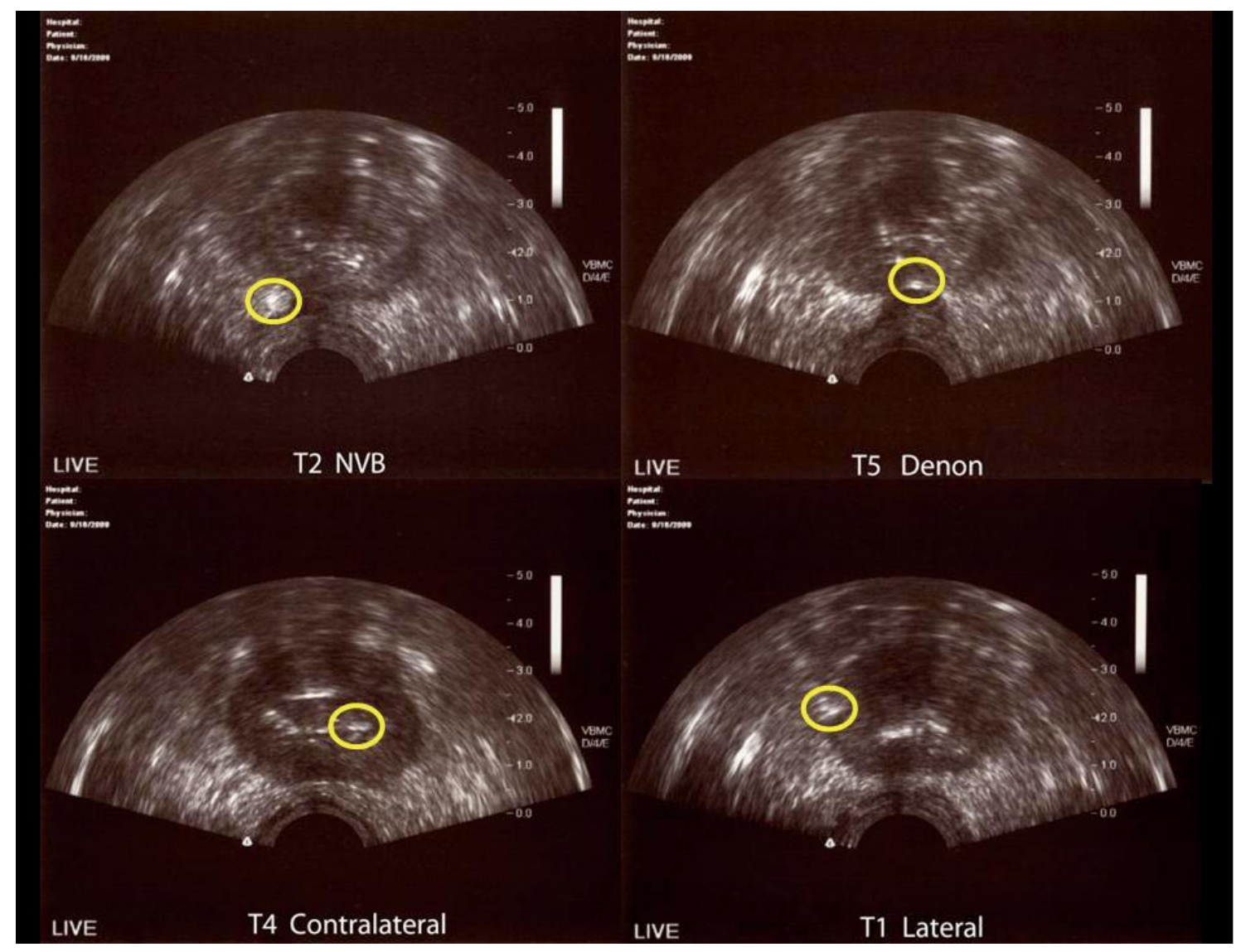

Fig. 2. Transverse TRUS-bx images demonstrating the lateral range of potential biopsy through a single grid coordinate (needle highlighted with circle) 


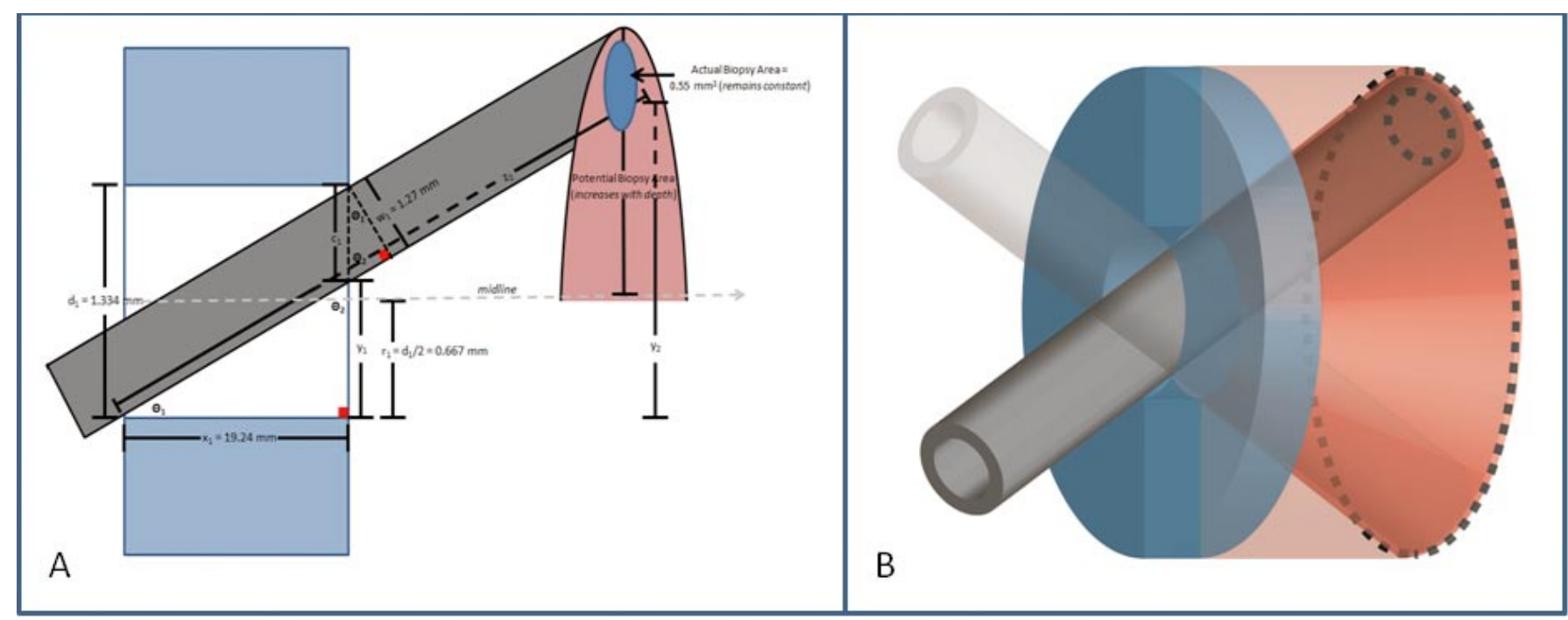

Fig. 3. Graphical representation: A geometric concepts of needle deviation, B area of potential biopsy through a single grid coordinate

Table 1. Accuracy of biopsy through a single grid coordinate at a given depth

\begin{tabular}{rllll}
\hline Biopsy depth, $\mathrm{mm}$ & \multicolumn{1}{l}{ Potential biopsy diameter, $\mathrm{mm}$} & Biopsy area, $\mathrm{mm}^{2}$ & Potential biopsy area, mm ${ }^{2}$ & Biopsy location certainty, $\%$ \\
\hline 50 & 1.7736 & 0.5515 & 2.4706 & 22.3 \\
100 & 2.1062 & 0.5515 & 3.4841 & 15.8 \\
150 & 2.4388 & 0.5515 & 4.6714 & 11.8 \\
200 & 2.7714 & 0.5515 & 6.0324 & 9.1 \\
250 & 3.1040 & 0.5515 & 7.5672 & 7.2 \\
\hline
\end{tabular}

location through a single grid hole. In this case, this was found to be due to needle bevel position as well as intentional minor directional alteration of the needle handle (outside the grid) to purposefully demonstrate the potential for inaccuracy. In an ideal system, the area biopsied would have $100 \%$ precision for the target area, which could be maximized this patient positioning and careful attention to each biopsy location, but this was not investigated in this work. However, in the actual system represented here, the biopsy needle is able to biopsy an area of $0.5515 \mathrm{~mm}^{2}$, but this can occur anywhere within the "cone" of biopsy possibility for each grid hole as shown graphically in figure $1 \mathrm{~b}$. Therefore, the accuracy or precision of a single biopsy with a $25-\mathrm{cm}$ needle can be up to 93\% inaccurate. In our example, this inaccuracy allowed us to reach almost the entire prostate through a single grid location, perhaps most graphically demonstrated by the needles shown completely missing the prostate anteriorly and posteriorly in the sagittal plane (fig. 1).

Tissue deformity and needle bending can lead to significant errors, as previously described with brachytherapy insertion [7]. Bevel-tip needles exert force asymmetrically and will cut tissue at an angle opposed to the direction that the tip of the needle is moving. This along with tissue deformity causes inaccuracies in sampling precision, a problem which is being explored with use of flexible needles and 2D finite element model systems [8]. Furthermore, tissue in homogeneity, deformation and physiological processes, such as respiration, flow of fluids, and edema, cause the needle to deviate from its intended path [9]. Finally, laxity within the needle hole based on the needle being smaller than the hole allows 
the needle to take a different path than that predicted by the numbering system on the grid. This can be largely handled by the surgeon being diligent during needle placement, which one might suspect might wane during the number of passes described during some of these procedures, exceeding 50 to 100 needle passes in some reports $[7,10]$. Furthermore, there is no way to overcome the inevitable deviation caused by the bevel, and the best that can be hoped for is that the bevel is in the same direction on each pass, so at least the deviation is predictable in relation to the holes in the grid.

The added risks associated with transperineal biopsy are not insignificant. General anesthesia is required in most cases, which alone is not an insignificant factor for this patient population. Furthermore, the risk of urinary retention is reported as approximately $10 \%$ in most published series, requiring catheterization and discharge with a Foley catheter, probably owing to the anesthetic [11, 12]. The transperineal approach is more costly based on operating time and anesthesia fees, plus the minor costs of the brachytherapy equipment including the stepping unit and template.

The major limitations of our study are that the images were all obtained in a single patient experience, and we intentionally attempted to demonstrate the full range of needle deviation. We sought to limit the potential for creating misleading images by assuring the grid was firmly against the perineum, and even doing so demonstrated that there were few areas of the prostate that could not be reached through the single grid coordinate. Furthermore, the needle was able to miss the prostate completely on several passes as shown in the figures.

\section{Conclusion}

There is potential for both technical as well as equipment associated error with transperineal template guided prostate biopsy. There is no evidence that this method is potentially highly inaccurate for localization of prostate cancer on repeat biopsy. Furthermore, our single patient example demonstrated that a core labeled with a hole in the brachytherapy grid could have come from almost anywhere in the prostate, or from completely outside the prostate. Although exaggerated for demonstration purposes, this failure of the grid to predictably define the location of the tissue core makes use of such "mapping" seem inadequate to guide focal therapy for prostate cancer.

\section{Acknowledgement}

We thank Stephen P Cavnar of the Biomedical Engineering Department at the University of Michigan for his help with the design and creation of the figures. Source of Funding is from Glickman Urological \& Kidney Institute, Cleveland Clinic.

\section{References}

$>1$ Terris MK: Extended field prostate biopsies: too much of a good thing? Urology 2000;55: 457-460.

$\checkmark 2$ Shepherd D, Keetch DW, Humphrey PA, Smith DS, Stahl D: Repeat biopsy strategy in men with isolated prostatic intraepithelial neoplasia on prostate needle biopsy. J Urol. 1996;156:460-462.

3 Remzi M, Djavan B, Wammack R, Momeni M, Seitz C, Erne B, Dobrovits M, Alavi S, Marberger M: Can total and transition zone volume of the prostate determine whether to perform a repeat biopsy? Urology 2003;61: 161-166.

4 Bouyé S, Potiron E, Puech P, Leroy X, Lemaitre L, Villers A: Transition zone and anterior stromal prostate cancers: zone of origin and intraprostatic patterns of spread at histopathology. Prostate 2009;69:105-113.
5 Igel TC, Knight MK, Young PR, Wehle MJ, Petrou SP, Broderick GA, Marino R, Parra RO: Systematic transperineal ultrasound guided template biopsy of the prostate in patients at high risk. J Urol 2001;165:15751579.

6 Pinkstaff DM, Igel TC, Petrou SP, Broderick GA, Wehle MJ, Young PR: Systematic transperineal ultrasound-guided template biopsy of the prostate: three-year experience. Urology 2004;65:735-739.

7 Merrick GS, Gutman S, Andreini H, Taubenslag W, Lindert DL, Curtis R, Adamovich E, Anderson R, Allen Z, Butler W, Wallner K: Prostate cancer distribution in patients diagnosed by transperineal templateguided saturation biopsy. Eur Urol 2007;52: 715-723.

8 Alterovitz R, Goldberg K, Okamura A: Sensorless motion planning for medical needle insertion in deformable tissues. Proceedings of the 2005 IEEE International Conference on Robotics and Automation, Barcelona, Spain, April 2005, p1652.
9 Misra S, Reed KB, Ramesh KT, Okamura AM: Observations of needle-tissue interactions. Conf Proc IEEE Eng Med Biol Soc 2009;2009:262-265.

10 Crawford ED, Wilson SS, Torkko KC, Hirano D, Stewart JS, Brammell C, Wilson RS, Kawata N, Sullivan H, Lucia MS, Werahera PN: Clinical staging of prostate cancer: a computer-simulated study of transperineal prostate biopsy. BJU Int 2005;96:999-1004.

$\checkmark 11$ Moran BJ, Braccioforte MH, Conterato DJ: Re-biopsy of the prostate using a stereotactic transperineal technique. J Urol 2006;176: 1376-1381.

12 Jones JS: Saturation biopsy for detecting and characterizing prostate cancer. BJU Int 2007; 99:1340-1344. 